ORIGINAL ARTICLE

\title{
Prevalence of sexually transmitted infections and mental health needs of female child and adolescent survivors of rape and sexual assault attending a specialist clinic
}

\author{
M Kawsar, A Anfield, E Walters, S McCabe, G E Forster
}

Sex Transm Infect 2004;80:138-141. doi: 10.1136/sti.2003.007252

See end of article for authors' affiliations

Correspondence to: Dr M Kawsar, Department of Genitourinary Medicine, Luton and Dunstable Hospital NHS Trust, Lewsey Road, Luton LU4 ODZ,UK; mokawsar@ hotmail.com

Accepted for publication 17 September 2003

\begin{abstract}
Objectives: To determine the prevalence of sexually transmitted infections (STIs) and the mental health needs of female child and adolescent survivors of rape and sexual assault who were referred to a specialist genitourinary medicine (GUM) clinic.

Method: Retrospective case notes review of 98 females aged 16 or less, who attended over a 5 year period (1996-2000).

Results: The overall prevalence of STIs was $26 \%$. Among the girls who were aged $0-12$ years $(n=16)$, one had gonorrhoea and another had Trichomonas vaginalis infection. Prevalence of STIs in those aged 1316 years, who were not sexually active before the index assault, was $24 \%$ and in those who gave a history of previous consensual sexual activity it was $39 \%(p=0.17)$. Chlamydial infection was more common among the girls who disclosed previous consensual sexual activity than in those did not disclose previous sexual activity $(p=0.012)$. The overall prevalence of vaginal candidiasis was $17 \%$ and bacterial vaginosis $13 \%$. More than one third of the study population gave a history of previous sexual, physical, or other abuse. $81 \%$ reported having current psychological difficulties. Mood changes and sleep disturbances were reported more frequently than other psychological symptoms; $15 \%$ attempted self harm. All types of psychological difficulties, except mood changes, were not affected by the time interval between index assault and first presentation to the clinic and the type of assailant. $29 \%$ had no involvement with social and mental health services before their attendance at the clinic

Conclusions: The prevalence of STIs among female child and adolescent survivors of rape and sexual assault attending a specialist clinic was high. The range of mental health and social difficulties was wide and multiple. The importance of an early assessment for the presence of STIs and mental health difficulties was demonstrated.
\end{abstract}

$\mathrm{S}$ exual abuse of children and adolescents is widespread. ${ }^{1}$ In one UK study, $27 \%$ of reported rapes were perpetrated against girls aged 15 years or less. ${ }^{2}$ There are serious physical, social, and mental health consequences for those experiencing sexual violence whether non-penetrative assault, single episode rape, or reoccurring sexual relationships of a non-consensual nature. ${ }^{3}$ Early victimisation is associated with an increase in further victimisation and risk taking behaviour in adolescence and adulthood-for example, unprotected sex with multiple partners and teenage pregnancy. ${ }^{145}$ This may also impede risk reduction intervention efforts to implement safer sex strategies. ${ }^{6}$ Victims who have been assaulted at a younger age have a high prevalence of psychological morbidity, later psychiatric disorder, and substance misuse. ${ }^{78}$ Multiple symptoms within the first few weeks after an assault may reflect the "normal" response to such a stressful event or perhaps an adjustment disorder. Severe, persistent single symptom profiles at a later time may reflect more serious psychopathology such as post-traumatic stress disorder and depression.

The aim of this study was to determine the prevalence of sexually transmitted infections, mental health, and social difficulties in female child and adolescent survivors of sexual assault/rape attending a specialist sexual assault service in an inner London genitourinary medicine (GUM) clinic.

\section{METHODS}

The study population comprised all females aged 16 years or less, who were referred over a 5 year period (1996-2000) to a specialist service for victims of sexual assault based in a specialist GUM clinic in London. Ethical approval was obtained from the East London and the City Health Authority research subcommittee. Data were collected retrospectively from the case notes using a standardised study proforma. Sexual and medical history, psychosocial problems, history of mental health difficulties, and current mental health issues of all survivors were routinely documented on clinic proforma.

Genital examination was offered in all cases. This includes screening for Neisseria gonorrhoeae, Chlamydia trachomatis, Trichomonas vaginalis, Candida species, and bacterial vaginosis, performed using standard methods. Pre-pubertal girls and those who were intolerant of or declined a speculum examination had external genital or vulvo-vaginal swabs taken. ${ }^{9}$ Oral and/or rectal samples were taken in those declaring attempted or full penetration or in those who had symptoms suggestive of infection at these sites. A first voided urine (FVU) sample was taken for chlamydial EIA or nucleic acid amplification (NAAT) test when it became available if other tests were declined. Blood tests for syphilis, hepatitis B, hepatitis C, and HIV serological markers were offered at presentation and at 3 month follow up, where appropriate. Culture for herpes simplex virus (HSV) was taken if clinically indicated. Pelvic inflammatory disease (PID), genital warts, and Pediculosis pubis were diagnosed clinically.

Antibiotic prophylaxis against bacterial STIs and hepatitis B vaccination was offered to all survivors of sexual assault/ rape. The study period was defined as follow up over 3 months from first presentation to the clinic. An assessment 
of STIs and risk of mental health problems was made on each visit. Blood tests and genital swabs were repeated if clinically indicated.

\section{Statistical analysis}

Prevalence of STIs, including chlamydial infection, in postpubertal girls (13-16 years) who were sexually active before the index assault and those who denied previous consensual sexual activity and in those who had full genital examination and those who declined speculum examination was compared using the $\chi^{2}$ test. Relation between the presence of an STI and psychological disturbance, current mental health symptoms against age, type of assailant, and the time interval between assault and attendance was also compared using the $\chi^{2}$ test. A statistical package, SAS version 8.2 , was used for all the calculation of $\mathrm{p}$ values.

\section{RESULTS}

\section{Demographic details}

A total of 126 females aged 16 years or less were referred to the clinic over the 5 year period, of whom 15 did not attend for assessment by a genitourinary physician. Twelve girls were seen at a different venue arranged by the paediatric team and were not included in the study; 99 girls were reviewed in clinic and 98 case notes were retrieved for analysis. The age range of the sample was 3-16 years, of whom 16 girls were aged less than 13 years. Assailants were all male; the youngest assailant recorded as aged 15 years. Assault by multiple assailants was reported in $15 \%(n=15)$ of the sample (range 2-7 assailants). Other demographic details of the study population are presented in table 1 .

\section{Contraception}

In those girls aged 13-16 years who gave a history of consensual sexual activity before the assault/rape $(n=28)$ four used condoms, five took the oral contraceptive pill, one received medroxyprogesterone acetate (Depo-provera), and 18 girls did not use any method of contraception.

Twenty four girls received emergency hormonal contraception; seven girls obtained it at presentation within our clinic, the remainder being prescribed it elsewhere. Seven individuals became pregnant and four of these may have been a direct consequent of the assault. Six girls underwent termination of pregnancy.

\section{Screening for STIs}

Of the sample $(n=98), 10$ females $(10 \%)$ declined any examination including urine test; 44 girls had a full genital screen including speculum examination, and 40 had external or vulvo-vaginal swabs without speculum examination. FVU was tested for Chlamydia trachomatis in four cases who declined genital examination; 16 of $72(22 \%)$ post-pubertal girls aged $13-16$ years declined speculum examination.

Thirteen of $98(13 \%)$ cases had antibiotic prophylaxis against bacterial STIs. Eight girls (8\%) had hepatitis B vaccination; none had HIV post-exposure prophylaxis; 69 $(70 \%)$ girls attended at least one appointment during follow up period.

\section{Prevalence of STIs}

Twenty three girls had at least one STI and the overall prevalence of STIs including non-specific PID was 26\% $(\mathrm{n}=88)$. Multiple STIs were diagnosed in two cases; one girl had gonorrhoea, Trichomonas vaginalis, and chlamydial infections; the other was diagnosed with genital warts and PID. Two of 16 (13\%) girls who were aged 12 years or less had an STI; one had gonorrhoea and another had Trichomonas vaginalis infection. Ten of $42(24 \%)$ girls aged $13-16$ years who did not disclose any consensual sexual activity before

\begin{tabular}{|c|c|}
\hline Demographic data & No (\%) \\
\hline \multicolumn{2}{|l|}{ Ethnicity } \\
\hline White European & $44(45)$ \\
\hline Black Afro-Caribbean & $27(28)$ \\
\hline Bangladeshi & $17(17)$ \\
\hline Other & $10(10)$ \\
\hline \\
\hline \multicolumn{2}{|l|}{ Referral pattern } \\
\hline Police including CPT ${ }^{*}$ and CID† & $62(63)$ \\
\hline Self referral & $9(9)$ \\
\hline Paediatrician & $8(8)$ \\
\hline General practitioner & 7 (8) \\
\hline Social services and others & $4(4)$ \\
\hline Not recorded & $8(8)$ \\
\hline \multicolumn{2}{|l|}{ Location of assault } \\
\hline UK & $96(97)$ \\
\hline Abroad & $2(3)$ \\
\hline \multicolumn{2}{|c|}{ Time between assault and attendance } \\
\hline$<7$ days & $17(17)$ \\
\hline $1-4$ weeks & $35(36)$ \\
\hline $1-3$ months & $22(23)$ \\
\hline $4-6$ months & $10(10)$ \\
\hline$>7$ months & $12(12)$ \\
\hline \multirow{2}{*}{\multicolumn{2}{|c|}{ Assailants }} \\
\hline & \\
\hline Stranger & $28(29)$ \\
\hline Acquaintance & $26(27)$ \\
\hline Family member & $22(22)$ \\
\hline Friend & 15 (15) \\
\hline Unknown by patient & $7(7)$ \\
\hline \multicolumn{2}{|l|}{ Nature of assault } \\
\hline $\begin{array}{l}\text { Vaginal penetration (attempted/ } \\
\text { actual) }\end{array}$ & $67(68)$ \\
\hline Oral penetration only & $1(1)$ \\
\hline Digital penetration only & $4(4)$ \\
\hline $\begin{array}{l}\text { More than one site including anal } \\
\text { penetration } \ddagger\end{array}$ & $21(22)$ \\
\hline Unknown by patient & $5(5)$ \\
\hline \multicolumn{2}{|l|}{ Family and social history } \\
\hline \multicolumn{2}{|l|}{ Accommodation } \\
\hline Living with parent $(\mathrm{s}) /$ carer & $77(79)$ \\
\hline Local authority & 19 (19) \\
\hline Not recorded & $2(2)$ \\
\hline Family problems & $20(20)$ \\
\hline Studying & $85(87)$ \\
\hline School based difficulties/truancy & $24(25)$ \\
\hline Learning difficulties & $6(6)$ \\
\hline Previous mental health problems & $30(31)$ \\
\hline Alcohol and other substance misuse & $31(32)$ \\
\hline \multirow{2}{*}{\multicolumn{2}{|c|}{ Previous abuse }} \\
\hline & \\
\hline Sexual & $37(38)$ \\
\hline Physical/emotional & $13(13)$ \\
\hline Previous STls & $4(4)$ \\
\hline Previous pregnancy & $4(4)$ \\
\hline
\end{tabular}

the index assault and 11 of 28 (39\%) girls who gave a history of previous consensual sexual activity, had at least one STI $(p=0.17)$. No STI was found in two girls aged 13-16 years whose sexual activity before the index assault was not recorded. Chlamydial infection was found in eight of 28 $(29 \%)$ girls who were involved in consensual sexual activity before the index assault compared to two of 42 (5\%) girls who were not involved in consensual sexual activity $(\mathrm{p}=0.012)$.

Of the girls who had a full genital screen and examination $(\mathrm{n}=44), 18(41 \%)$ were found to have at least one STI. Of those who had FVU, external genital, or vulvo-vaginal swabs $(\mathrm{n}=44)$, five $(11 \%)$ girls had at least one STI $(\mathrm{p}=0.0016)$. Ten girls in the "full examination" group and none in the other group were diagnosed with chlamydial infection $(\mathrm{p}=0.008)$. 
Overall, $15(17 \%)$ girls had vaginal candidiasis and 11 ( $13 \%)$ had bacterial vaginosis $(n=88)$. There were no cases of syphilis, hepatitis B or hepatitis C virus $(n=57)$, or HIV infection among those tested $(\mathrm{n}=33)$.

\section{Mental health and social difficulties}

Fifty eight of 98 (59\%) females aged 16 years or less described psychosocial difficulties before the index assault. These included previous sexual abuse, other abuse, family problems, poor school attendance, learning difficulty, and alcohol misuse (table 1$)$. Thirty $(31 \%)$ had one or more mental health difficulties before the assault. These included deliberate self harm 13 (13\%), depression 13 (13\%), behavioural problems eight $(8 \%)$, and eating difficulties four $(4 \%)$.

Ninety one out of 93 girls aged 10-16 years were included in the analysis of current mental health problems; five girls below the age of 10 years were excluded for developmental reasons. Two girls aged 10-16 years were also excluded from the analysis because of the absence of documented current psychosocial information in the case notes; 74 of 91 (81\%) girls reported current, often multiple, symptoms at presentation, including mood changes in 50 (55\%), sleep disturbance in $36(40 \%)$, anxiety in $30(33 \%)$, appetite change in 14 (15\%), and psychosomatic symptoms in seven (8\%). Thoughts of self harm occurred in 32 (35\%) and 14 (15\%) made attempts after the assault. Attempted self harm included overdoses in nine cases, cutting in two cases, and attempted hanging and jumping in three cases, with the majority presenting in the first 6 months of the assault. Details of the recorded symptoms were compared to age at presentation, time interval between assault and first presentation, and the type of assailants (table 2). Both younger (aged 10-12 years) and older adolescents (aged 13-16 years) reported a wide range of current mental health problems during the follow up period: 32 of 91 (35\%) girls reported more than three psychological symptoms and 30 of them were aged 13-16 years. Mood changes were higher in those presenting after 1 month of the index assault $(\mathrm{p}=0.001)$.

Further analysis of the results showed no significant relation between the presence of an STI and psychological disturbance $(p=0.84)$. Twenty six $(29 \%)$ of these young people aged 10-16 years had no involvement with social services or child and adolescent mental health services at the initial presentation to our clinic and these girls were referred to the appropriate services for further assessment and follow up.

\section{DISCUSSION}

The reported prevalences of STIs in girls and boys where sexual abuse was suspected were low in the United Kingdom. ${ }^{10}{ }^{11}$ However, the risk of infection depends upon the prevalence of STIs in the abusers and abused population, the organism, and the type and site of the assault. Recent data suggest a continued rise in the number of new cases of STIs diagnosed within GUM clinics in the United Kingdom. The largest increase in cases of gonorrhoea and genital chlamydial infection was seen among teenagers of both sexes, and they remain key groups in STI transmission. ${ }^{12}$ More recently, Creighton et al demonstrated higher rate of STIs in females aged 16 years or less attending a London clinic. However, the authors did not report on the number of girls who were sexually assaulted/raped in their study. ${ }^{13}$

Our study showed that the overall prevalence of STIs in female child and adolescent survivors of rape and sexual assault attending a specialist GUM clinic was high. Chlamydial infection was significantly more common in post-pubertal girls who were involved in consensual sexual activity before the index assault. The study also demonstrated that the prevalence of STIs was lower in those who declined a speculum examination than in those who underwent the examination. This may reflect differences in the methods used or true population differences between the two groups. Prospective studies are needed to explain this. Furthermore, this study supports other published studies in emphasising the importance of screening for STIs in survivors of rape and sexual assault whether or not they disclose a history of previous consensual sexual activity. ${ }^{14} 15$

Ten per cent of the study population declined screening for STIs because of its perceived invasive nature. School based screening programmes for chlamydia and/or gonorrhoea in the United States and, more recently, pilot studies for genital chlamydial infection in England, have demonstrated that less invasive techniques such as urine ligase chain reaction (LCR) test were more acceptable to young people. ${ }^{16-19}$ Non-invasive DNA amplification tests to identify $C$ trachomatis and other sexually transmitted organisms, would also be more acceptable for STI screening in these young survivors. Before these assays could be used for medicolegal purposes, studies comparing these techniques with the more established methods would need to be undertaken as they are largely untested in this age group. ${ }^{20}$

There were a number of risk factors within the study population, which could increase the likelihood of further abuse and future unwanted pregnancies, STIs, and psychological difficulties. More than one third of girls reported previous sexual abuse. A history of mental health problems, substance misuse, and learning difficulty indicated further individual vulnerability. Environmental factors including school attendance difficulties, leaving the family home, family dysfunction, lack of social and mental health support were frequent in the study population. The prevalence of mood, sleep and appetite disturbances was also high.

Table 2 Symptoms recorded after assault compared to time interval, age at presentation, and type of assailant(s)

\begin{tabular}{|c|c|c|c|c|c|c|c|}
\hline & $\begin{array}{l}\text { Mood changes } \\
\text { No }(\%)\end{array}$ & $\begin{array}{l}\text { Sleep disturbance } \\
\text { No }(\%)\end{array}$ & $\begin{array}{l}\text { Anxiety } \\
\text { No }(\%)\end{array}$ & $\begin{array}{l}\text { Thought of } \\
\text { self harm } \\
\text { No }(\%)\end{array}$ & $\begin{array}{l}\text { Attempted } \\
\text { self harm } \\
\text { No }(\%)\end{array}$ & $\begin{array}{l}\text { Appetite changes } \\
\text { No }(\%)\end{array}$ & $\begin{array}{l}\text { Psychosomatic } \\
\text { symptoms } \\
\text { No }(\%)\end{array}$ \\
\hline \multicolumn{8}{|l|}{ Age at presentation } \\
\hline $10-12$ years $(n=12)$ & $5(42)$ & $3(25)$ & $5(42)$ & $1(8)$ & $1(8)$ & $1(8)$ & 0 \\
\hline $13-16$ years $(n=79)$ & $45(57)$ & $33(42)$ & $25(32)$ & $31(41)$ & $13(16)$ & $13(16)$ & $7(9)$ \\
\hline \multicolumn{8}{|l|}{ Time interval since assault } \\
\hline$<1$ month $(n=46)$ & $17(37)$ & $20(43)$ & $18(39)$ & $18(39)$ & $6(13)$ & $9(20)$ & $3(7)$ \\
\hline $1-6$ months ( $n=32)$ & $25(78)$ & $13(40)$ & $9(28)$ & 11 (34) & $6(19)$ & $2(6)$ & 1 (3) \\
\hline$\geqslant 7$ months $(n=13)$ & $8(62)$ & $3(23)$ & $3(23)$ & $3(23)$ & $2(15)$ & $3(23)$ & $3(23)$ \\
\hline \multicolumn{8}{|l|}{ Assailants } \\
\hline Stranger/unknown $(n=33)$ & $17(52)$ & $14(42)$ & $9(27)$ & $10(30)$ & $5(15)$ & $3(9)$ & $2(6)$ \\
\hline Acquaintance/friend ( $n=38)$ & $27(71)$ & $17(45)$ & $16(42)$ & $17(45)$ & $7(18)$ & $8(21)$ & $2(5)$ \\
\hline Family $(n=20)$ & $6(30)$ & $5(25)$ & $5(25)$ & $5(25)$ & $2(10)$ & $3(15)$ & $3(15)$ \\
\hline
\end{tabular}




\section{Key messages}

- Prevalence of STls was high among female child and adolescent survivors of sexual assault/rape

- Genital chlamydial infection was more common in post-pubertal girls who were involved in consensual sexual activity

- Psychosocial difficulties were common and multiple in young survivors of sexual assault/rape

- An early assessment of both physical and mental health is important in these survivors

Deliberate self harm was a common problem in these young survivors as reported in other studies. ${ }^{81-23}$

There were some limitations in this retrospective study. Those attending the clinic were a self selected group. The findings cannot be generalised to survivors not making contact with services. A significant proportion of adolescent survivors of sexual violence may not be able to disclose their history unless specifically asked. ${ }^{24}$ Inquiring about mental health problems requires specialist training and expertise, being dependent upon the young person's recall of events. In addition, the method for eliciting mental health symptoms was not standardised in this study. Furthermore, different types of assessment used and poor follow up may have contributed to an underestimation of the true prevalence of STIs among these survivors.

In conclusion, our study demonstrated a high prevalence of STIs, mental health, and social difficulties among female child and adolescent survivors of sexual assault/rape, reinforcing the importance of early physical and mental health assessment of these young people. The development of specialist services, within the United Kingdom, where the needs of child and adolescent survivors of sexual assault/rape can be addressed, is urgently required.

\section{ACKNOWLEDGEMENTS}

We wish to thank Kevin Jones and Ulrike Krause for collecting data and Jackie Turner for her help in statistical analysis.

\section{CONTRIBUTORS}

MK and AA, data collection, data analysis, manuscript preparation; SM, data collection, manuscript preparation; EW and GEF, study design, data analysis, manuscript preparation.

\section{Authors' affiliations}

M Kawsar, Department of Genitourinary Medicine, Luton and Dunstable Hospital NHS Trust, Lewsey Road, Luton LU4 ODZ, UK

A Anfield, E Walters, Department of Child and Adolescent Psychiatry, Royal London Hospital, Barts and London NHS Trust, Whitechapel, London, UK

S McCabe, G E Forster, Ambrose King Centre, Royal London Hospital, Barts and the London NHS Trust, Whitechapel, London, UK

Funding: not needed.
Ethical approval obtained from East London and the City Health Authority research committee.

Mental health needs of sexually abused girls presenting to a specialist genitourinary medicine clinic was presented at the Fourth European Conference Association for Child Psychology and Psychiatry 2000, London (Poster). Prevalence of sexually transmitted infections was presented at the ISSTDR and IUSTI conference, 2001, Berlin (Poster No 31, abstract: Int J STDs AIDS 2001;12(suppl 2): 179.

\section{REFERENCES}

1 Browne A, Finkelhor D. Impact of child sexual abuse: a review of the research. Psychol Bull 1986;99:66-77.

2 Harris J, Grace S. A question of evidence? Investigating and prosecuting rape in the 1990s. Home Office Research Study 196. London: Home Office, 1999.

3 Jeffrey TB, Jeffrey KK. The psychological aspects of sexual abuse in adolescents. Curr Opinn Obstet Gynaecol 1991;36:825-31.

4 Heise L. Violence against women; the hidden health burden. World Bank statement 1994: No 255

5 Keane FE, Young SM, Boyle HM. The prevalence of previous sexual assault among routine female attenders at a department of genitourinary medicine. Int J STD AIDS 1996;7:480-4.

6 Greenberg JB. Childhood sexual abuse and sexually transmitted diseases in adults: a review of and implications for STD/HIV programmes. Int J STD AIDS $2001 ; 12: 777-83$.

7 Kendall-Tackett KA, Williams LM, Finkelhor D. Impact of sexual abuse on children: a review and synthesis of recent empirical studies. Psychol Bull 1993;113:164-80.

8 Frothingham TE, Hobbs $C J$, Wynne JM, et al. Follow-up study eight years after diagnosis of sexual abuse. Arch Dis Child 2000;83:132-4.

9 Clinical Effectiveness Group (Association for Genitourinary Medicine and the Medical Society for the Study of Venereal Diseases). National Guideline on the management of suspected sexually transmitted infections in children and young people. Sex Transm Infect 2002;78:324-31.

10 Robinson AJ, Watkeys JEM, Ridgway GL. Sexually transmitted organisms in sexually abused children. Arch Dis Child 1998;79:356-8.

11 Hobbs CJ, Wynne JM. Sexual abuse of English boys and girls: the importance of anal examination. Child Abuse and Neglect 1989;13:195-210.

12 CDSC. Young people bear the brunt of increasing sexually transmitted infections in England. CDR Weekly 2000;10:277-80.

13 Creighton S, Edwards S, Welch J, et al. News from the front line: sexually transmitted infections in teenagers attending a genitourinary clinic in south east London. Sex Transm Infect 2002;78:349-51.

14 Peipert JF, Domagalski LR. Epidemiology of adolescent sexual assault. Obstet Gynecol 1994;84:867-71.

15 American Academy of Pediatrics, Committee on Adolescence. Care of the adolescent sexual assault victim. Pediatrics 2001;107:1476-9.

16 Cohen DA, Nsuami M, Etame RB, et al. A school- based Chlamydia control program using DNA amplification technology. Pediatrics 1998;101:E1.

17 Burstein GR, Waterfield G, Joffe A, et al. Screening for gonorrhea and chlamydia by DNA amplification in adolescents attending middle school health centers. Opportunity for early intervention. Sex Transm Dis 1998;25:395-402.

18 Department of Health. A pilot study of opportunistic screening for genital Chlamydia trachomatis infection in England (1999-2000)-Portsmouth pilot site. London: DoH, 2002.

19 Department of Health. A pilot study of opportunistic screening for genital Chlamydia trachomatis infection in England (1999-2000)-Wirral pilot site. London: DoH, 2002.

20 Hammerschlag $M$. Sexually transmitted infections in sexually abused children: medical and legal implications. Sex Transm Infect 1998;74:167-74.

21 Molnar BE, Buka SL, Kessler RC. Child sexual abuse and subsequent psychopathology: results from the National Co-morbidity Survey. Am J Public Health 2001;91:753-8.

22 Bulik CM, Prescott CA, Kendler KS. Features of childhood sexual abuse and the development of psychiatric and substance use disorders. Br J Psychiatry 2001;179:444-9.

23 Brown J, Cohen P, Johnson JG, et al. Childhood abuse and neglect: specificity of effects on adolescent and young adult depression and suicidality. J Am Acad Child Adolesc Psychiatry 1999;38:490-6.

24 McLellan F. US paediatricians advised to ask about sexual assault (news). Lancet 2001;357:951. 